\title{
Solusi Persamaan Laplace pada Koordinat Bola
}

\author{
Ahmad Zaki ${ }^{1}$, Syafruddin Side ${ }^{1}$, dan Nurhaeda ${ }^{1, \text { a) }}$ \\ ${ }^{1} J u r u s a n$ Matematika, Fakultas Matematika dan Ilmu Pengetahuan Alam \\ Universitas Negeri Makassar \\ a)nhaeda24@gmail.com
}

\begin{abstract}
Abstrak. Penelitian ini mengkaji mengenai persamaan Laplace pada koordinat bola dan menerapkan metode pemisahan variabel dalam menentukan solusi persamaan Laplace Persamaan Laplace merupakan salah satu jenis persamaan diferensial parsial yang banyak digunakan untuk memodelkan permasalahan dalam bidang sains. Bentuk umum persamaan Laplace pada dimensi tiga dimana u adalah fungsi skalar dengan menggunakan metode pemisahan variable diperoleh persamaan Laplace dimensi tiga pada koordinat bola. Hasil penelitian ini mendapatkan penyelesaian persamaan Laplace pada koordinat bola dalam bentuk variabel terpisah dengan tidak menggunakan nilai batas. Hubungan koordinat kartesian dan koordinat bola pada persamaan Laplace dapat ditentukan dalam persamaan Laplace dan memperoleh solusi dengan menggunakan koordinat bola.
\end{abstract}

Kata Kunci: Koordinat Bola, Pemisahan Variabel, dan Persamaan Laplace.

\begin{abstract}
This study examines Laplace equations on spherical coordinates and applies variable separation methods in determining Laplace equation solutions Laplace equations are one type of partial differential equation that is widely used to model problems in the field of science. The general form of the Laplace equation in the third dimension in which $u$ is a scalar function using the separation method of the variable is obtained by the third dimension Laplace equation on spherical coordinates. The result of this research get solution of Laplace equation on spherical coordinate in the form of separate variable by not using boundary value. The relationship of cartesian coordinates and spherical coordinates to the Laplace equation can be determined in the Laplace equation and obtain solutions using spherical coordinates.

Keywords: Spherical Coordinat Variabel Separation, and Laplace Equation.
\end{abstract}

\section{PENDAHULUAN}

Persamaan diferensial merupakan salah satu cabang ilmu matematika yang dipelajari oleh banyak orang dan sebagian sudah diterapkan dalam kehidupan nyata seperti halnya pemodelan matematika yang memiliki perang dalam bidang teknik, biologi, dan lain-lain, tetapi ada juga yang digunakan untuk mengembangkan materi yang sudah didapat sehingga memperoeh suatu pernyataan yang benar dan dapat dibuktikan secara matematis. Persamaan diferensial mempelajari berbagai macam materi yang berguna pada penelitian. Salah satunya persamaan laplace yang merupakan materi dalam persamaan diferensial. Persamaan Laplace merupakan salah satu yang terpenting dari semua persamaan diferensial dalam terapan matematika Boyce (2004).

Persamaan diferensial parsial adalah persamaan yang memuat turunan parsial satu atau lebih variabel tak bebas terhadap dua atau lebih variabel bebas. Dalam persamaan diferensial parsial 
tingkat dua dikenal persamaaan Lapalace dengan bentuk umum: $\nabla^{2} u=0$ dengan $\nabla^{2} u=\frac{\partial^{2} u}{\partial x^{2}}+$ $\frac{\partial^{2} u}{\partial y^{2}}=0 \quad$ dan $\nabla^{2} u=\frac{\partial^{2} u}{\partial x^{2}}+\frac{\partial^{2} u}{\partial y^{2}}+\frac{\partial^{2} u}{\partial z^{2}}=0$ merupakan operasi Laplace dua dan tiga dimensi (Taylor dalam Side, 2014). Persamaan Laplace dimensi tiga terdiri dari tiga variabel bebas $x, y$ dan $z$ untuk menyatakan posisi benda di dalam ruan $\left(R^{3}\right)$ dibutuhkan suatu sistem koordinat. Sistem koordinat adalah suatu cara yang digunakan untuk menentukan letak suatu titik pada bidang $\left(R^{2}\right)$ atau ruang $\left(R^{3}\right)$. Pada bidang $\left(R^{2}\right)$, letak titik pada umumnya dinyatakan dalam koordinat Cartesius dan koordinat kutub. Sedangkan pada ruang $\left(R^{3}\right)$ letak suatu titik pada umumnya dinyatakan dalam koordinat Cartesius, koordinat tabung dan koordinat bola. Koordinat Cartesian tiga dimensi $(x, y, z)$ dapat diubah menjadi koordinat tabung dan koordinat bola. Hubungan dari ketiganya, jika $u(x, y, z)$ adalah titik dalam koordinat Cartesian, maka $u(r, \theta, z)$ adalah titik dalam koordinat tabung dan $u(r, \theta, \phi)$ adalah titik dalam koordinat bola Purnomo(2016).

Persamaan Laplace sebelumnya telah diterapkan oleh Faradillah (2011) dalam penelitiannya. Ia menggunakan metode pemisahan variabel (separation of variables) untuk memperoleh solusi analitik persamaan Laplace tersebut sedangkan untuk memperoleh penyelesaian khususnya Ia menggunakan metode beda hingga (finite difference). Selain itu Aziz dan Chandra (2015) memperkenalkan Metode variabel terpisah dalam mencari solusi dengan menggunakan nilai batas. Kemudian menunjukkan solusi dari permasalahan nilai batas dalam domain yang berbeda, yaitu empat permasalahan di ruang Euclid berdimensi dua dan satu permasalahan dalam ruang Euclid berdimensi tiga.

Pada penelitian ini membahas mengenai solusi persamaan Laplace dimensi tiga pada koordinat bola. Sebelum menentukan solusi, terlebih dahulu mengidentiikasi dan menganalisis penyelesaian analitik persamaan Laplace pada koordinat bola serta menerapkan metode variabel terpisah dalam menentukan solusi persamaan Laplace pada koordinat bola.

\section{Persamaan Diferensial Parsial}

Persamaan diferensial parsial adalah persamaan diferensial yang menyangkut satu atau lebih fungsi (variabel tak bebas) beserta turunannya terhadap lebih dari satu variabel bebas (Anggoro dalam Side, 2014).

Bentuk umum persamaan diferensial parsial adalah

$$
F\left(x, y, \ldots, u, u_{x}, u_{y}, \ldots, u_{x x}, u_{y y}, \ldots\right)=0
$$

Persamaan diferensial parsial linier adalah suatu bentuk persamaan diferensial parsial yang berderajat satu dalam peubah tak bebasnya dan turunnan parsialnya. Ketika ada sebuah fungsi $w(x, y)$ yang bergantung pada dua variable $x$ dan $y$ dan jika diturunkan terhadap $y$ dan $x$ bernilai konstan.

Adapun bentuk umum persamaan diferensial parsial linier orde-2 diberikan dengan

$$
A u_{x x}+B u_{x y}+C u_{y y}+D u_{x}+E u_{y}+F u=G
$$

dengan $A, B, C, D, E, F$ dan $G$ adalah fungsi-fungsi bergantung pada $x$ dan $y$.

\section{Persamaan Laplace}

Persamaan Laplace merupakan salah satu jenis persamaan diferensial parsial yang banyak digunakan untuk memodelkan permasalahan dalam bidang sains. Persamaan ini merupakan contoh klasik dari persamaan eliptik dan merupakan jenis persamaan diferensial linier orde dua dengan dua peubah. Persamaan Laplace yang bentuk umumnya $\Delta v=0$ sering dijumpai pada teori perpindahan panas, mekanika fluida, elastisitas, elektrostatis dan masalah mekanika dan 
fisika lainnya Salah satu permasalahan dalam persamaan Laplace yang akan dibahas pada penelitian ini yaitu masalah distribusi suhu dalam keadaan tunak pada sebuah logam dalam dimensi dua berbentuk plat.

Masalah penyelesaian persamaan $\nabla^{2} v=0$ di dalam daerah $R$ sering disebut Dirichlet problem, dengan $v$ sebagai fungsi yang di ketahui pada batas $R$. Persamaan Laplace dapat dituliskan dalam beberapa bentuk bergantung pada sistem koordinat yang digunakan yaitu:

1. Persamaan Laplace dalam dua dimensi

$\frac{\partial^{2} v}{\partial x^{2}}+\frac{\partial^{2} v}{\partial y^{2}}=0$ pada sistem koordinat kartesius

$\frac{1}{r} \frac{\partial}{\partial r}\left(r \frac{\partial v}{\partial r}\right)+\frac{1}{r^{2}} \frac{\partial^{2} v}{\partial \varphi^{2}}=0$ pada sistem koordinat polar

dengan, $x=r \cos \varphi, y=r \sin \varphi$ dan $r=\sqrt{x^{2}+y^{2}}$

2. Persamaan Laplace dalam tiga dimensi

$$
\nabla^{2} v=\frac{\partial^{2} v}{\partial x^{2}}+\frac{\partial^{2} v}{\partial y^{2}}+\frac{\partial^{2} v}{\partial z^{2}}=0
$$

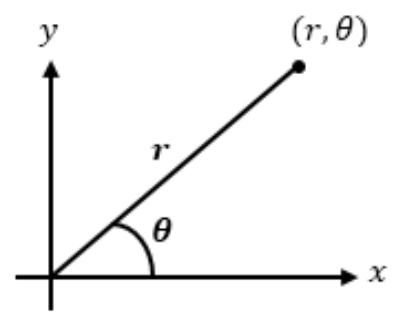

GAMBAR 1. Koordinat Kartesius

$$
\nabla^{2}=\frac{1}{r} \frac{\partial}{\partial r}\left(r \frac{\partial v}{\partial r}\right)+\frac{1}{r^{2}} \frac{\partial^{2} v}{\partial \varphi^{2}}+\frac{\partial^{2} v}{\partial z^{2}}=0
$$

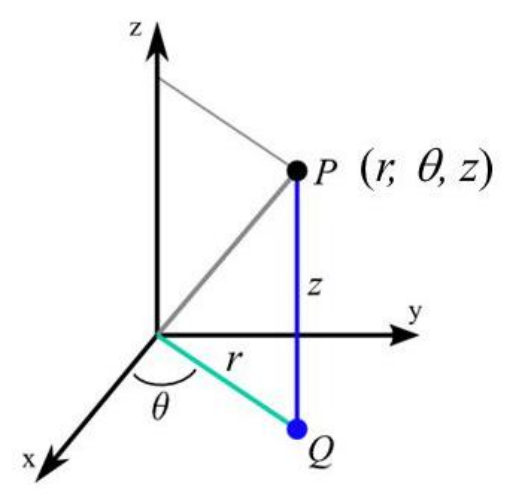

GAMBAR 2. Koordinat Silinder

$$
\nabla^{2}=\frac{1}{\rho^{2}} \frac{\partial}{\partial \rho}\left(\rho^{2} \frac{\partial v}{\partial \rho}\right)+\frac{1}{\rho^{2} \sin \theta} \frac{\partial}{\partial \theta}\left(\sin \theta \frac{\partial v}{\partial \theta}\right)+\frac{1}{\rho^{2}} \frac{1}{\sin ^{2} \theta} \frac{\partial^{2} v}{\partial \phi^{2}}=0
$$




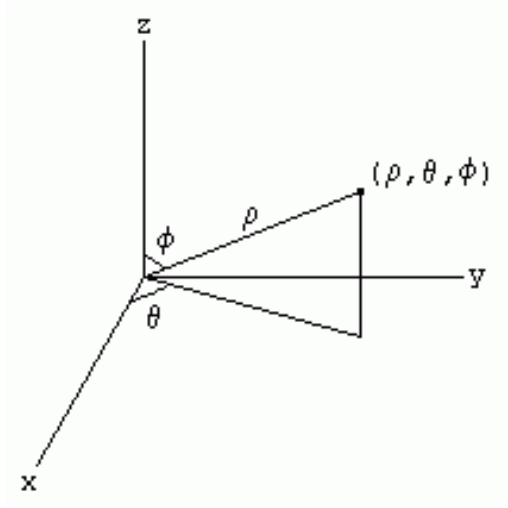

GAMBAR 3. Koordinat Bola

\section{Metode Pemisahan Variabel}

Metode pemisahan variabel adalah teknik klasik yang evektif dalam menyelesaikan beberapa tipe persamaan diferensial parsial. Pada Metode Variabel Terpisah, solusi $u(x, y)$ diasumsikan mempunyai bentuk

Definisi 1. Kusumah, (1989):

$$
u(x, y)=X(x) Y(y)
$$

Sebuah persmaan diferensial yang berbentuk $F(x) G(y) d x+f(x) g(y)=0$ disebut persamaan diferensial dengan variabel terpisah.

\section{Persamaan Diferensial Linear Cauchy}

Bentuk umum persamaan diferensial linear Cauchy:

$$
P_{0} x^{n} \frac{d^{n} y}{d x^{n}}+P_{1} x^{n-1} \frac{d^{n-1} y}{d x^{n-1}}+\cdots+P_{n-1} x \frac{d y}{d y}+P_{n} y=Q(x)
$$

atau dapat ditulis dalam polinomial operator $\mathrm{D}$.

$$
\left(P_{0} x^{n} D^{n}+P_{1} x^{n-1} D^{n-1}+\cdots+P_{n-1} x D+P_{n}\right) y=Q(x)
$$

dengan $P_{0} \neq 0, P_{1}, \ldots, P_{n}$ adalah konstan.

untuk menyelesaikan persamaan diferensial ini, dilakukan transformasi $x=e^{z}$ untuk mereduksi persamaan diferensial menjadi persamaan diferensial linier orde $n$ dengan koefisien konstan, yaitu:

transformasi $x=e^{z}$ atau $\ln x=z$

kemudian jika $D$ didefinisikan oleh $D=\frac{d}{d z}$ maka:

$$
\begin{gathered}
x D y=D y \\
x^{2} D^{2} y=D(D-1) y \\
x^{3} D^{3} y=D(D-1)(D-2) y \\
\ldots \\
x^{n} D^{n} y=D(D-1)(D-2)(D-3) \ldots(D-n+1) y
\end{gathered}
$$

dan persamaan diferensial tereduksi menjadi:

$\left[P_{0} D(D-1)(D-2)(D-3) \ldots(D-n+1)+P_{1} D(D-1)(D-2) \ldots(D-n+2)+\cdots+P_{n-1} D+P_{n}\right] y=Q\left(e^{z}\right)$

Berdasarkan jenis akar-akar dari persamaan karakteristik ada tiga kasus yang perlu diperhatikan didalam menentukan solusi umum Kartono, (1994): 
Kasus I: semua akar riil dan berbedaa, yaitu:

$$
\lambda_{1} \neq \lambda_{2} \neq \lambda_{3} \neq \lambda_{4} \neq \ldots \neq \lambda_{n-1} \neq \lambda_{n}
$$

Solusi umum persamaan diferensial adalah:

$$
y=c_{1} e^{\lambda_{1} x}+c_{2} e^{\lambda_{2} 2 x}+c_{3} e^{\lambda_{3} 3 x}+\cdots+c_{n} e^{\lambda_{n} n x}
$$

memuat $n$ solusi bebas linier dengan $n$ konstanta sebarang.

Kasus II: jika $\lambda_{1}=\lambda_{2} \neq \lambda_{3} \neq \lambda_{4} \neq \ldots \neq \ldots \lambda_{n-1} \neq \lambda_{n}$

Solusi umum persamaaan diferensial adalah:

$$
y=c_{1} e^{\lambda_{1} x}+c_{2} e^{\lambda_{2} x}+c_{3} e^{\lambda_{3} x}+\cdots+c_{n} e^{\lambda_{n} x}
$$

Secara umum, jika $\lambda$ terjafi sebanyak $r$ kali, maka solusi umum persamaan diferensial ini adalah

$$
y=\left(c_{1}+c_{2} x+c_{3} x^{2}+\cdots+c_{n} x^{r-1}\right) e^{\lambda x}+c_{r+1} e^{\lambda_{r+1} x}+\cdots+c_{n-1} e^{\lambda_{n-1} x}+c_{n} e^{\lambda x}
$$

Kasus III: Beberapa akarnya merupakan akar kompleks, Jika $P_{0}, P_{1}, P_{2}, \ldots, P_{n}$ adalah riil dan jika $a+b i$ adalah akar kompleks dan demikian juga dengan $a-b i$ (dengan $a$ dan $b$ adalah riil) maka solusi umum yang berkaitan dengan akar kompleks ini adalah:

$$
y=e^{a x}\left[c_{1} \cos b x+c_{2} \sin b x\right]
$$

\section{METODE PENELITIAN}

Penelitian ini merupakan kajian teori mengenai sistem persamaan diferensial parsial yang bertujuan untuk menentukan solusi persamaan Laplace pada koordinat bola. Dilakukan pada tahun 2018. Penelitian ini membahas mengenai solusi persamaan Laplace dimensi tiga pada koordinat bola. Proses dalam menentukan solusi umum terdapat dua tahap, yaitu yang pertama terlebih dahulu mengidentiikasi dan menganalisis penyelesaian analitik untuk mendapatkan persamaan Laplace pada koordinat bola selanjutnya dalam proses menentukan solusi persamaan Laplace pada koordinat bola menerapkan metode variabel terpisah.

\section{HASIL DAN PEMBAHASAN}

\section{Prosedur matematis persamaan Laplace pada koordinat bola}

Untuk menyatakan posisi sebuah benda di dalam ruang, dibutuhkan suatu sistem koordinat yang memiliki pusat koordinat dan sumbu koordinat. Sistem koordinat yang paling umum adalah koordinat kartesius. Koordinat kartesius dimensi tiga memiliki pusat di $P$ dan dua sumbu koordinat yang saling tegak lurus, yaitu $x$ dan $y$.

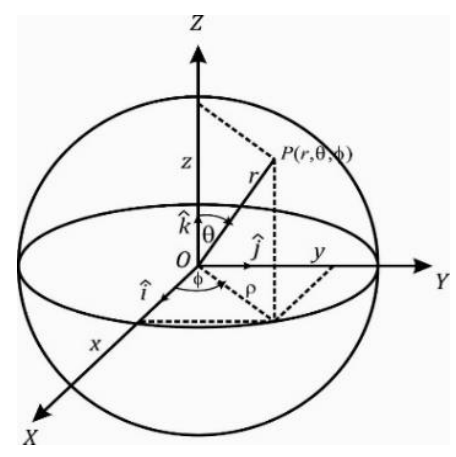

GAMBAR 4: koordinat Bola 
Hubungan antara koordinat kartesius dengan koordinat bola $u(r, \theta, \phi)$ dapat dilihat pada gambar 4 maka diperoleh persamaan (2)

dengan $r \geq 0$,

$$
\begin{gathered}
x=r \sin \theta \cos \phi \\
y=r \sin \theta \sin \phi \\
z=r \cos \theta
\end{gathered}
$$

pada gambar 1 diperoleh persamaan Laplace dimensi tiga koordinat kartesius

$$
\nabla^{2} u=\frac{\partial^{2} u}{\partial x^{2}}+\frac{\partial^{2} u}{\partial y^{2}}+\frac{\partial^{2} u}{\partial z^{2}}=0
$$

Menentukan turunan parsial $x, y$, dan $z$ terhadap $r, \theta$ dan $\phi$ dan turunan parsial $x, y$ dan $z$ dari persamaan (2) terhadap $r, \theta$ dan $\phi$ dengan menggunakan persamaan (1) diperoleh persamaan (3), (4), dan (5)

$$
\begin{gathered}
\frac{\partial u}{\partial r}=\frac{\partial u}{\partial x} \sin \theta \cos \phi+\frac{\partial u}{\partial y}(\sin \theta \sin \phi)+\frac{\partial u}{\partial z}(\cos \theta) \\
\frac{\partial u}{\partial \theta}=\frac{\partial u}{\partial x}(r \cos \theta \cos \phi)+\frac{\partial u}{\partial y}(r \cos \theta \sin \phi)+\frac{\partial u}{\partial z}(-r \sin \theta) \\
\frac{\partial u}{\partial z}=\frac{\partial u}{\partial x}(-r \sin \theta \sin \phi)+\frac{\partial u}{\partial y}(r \sin \theta \cos \phi)
\end{gathered}
$$

Asumsikan bahwa $\frac{\partial^{2} u}{\partial x \partial r}, \frac{\partial^{2} u}{\partial r \partial x}, \frac{\partial^{2} u}{\partial y \partial r} \frac{\partial^{2} u}{\partial r \partial y}, \frac{\partial^{2} u}{\partial z \partial r}$ dan $\frac{\partial^{2} u}{\partial r \partial z}$ pada persamaan (3), (4), dan (5) adalah fungsi kontinu. Maka diperoleh persamaan (6), (7), dan (8)

$$
\begin{gathered}
\frac{\partial^{2} u}{\partial r^{2}}=\frac{\partial^{2} u}{\partial x^{2}}\left(\sin ^{2} \theta \cos ^{2} \phi\right)+\frac{\partial^{2} u}{\partial y^{2}}\left(\sin ^{2} \theta \sin ^{2} \phi\right)+\frac{\partial^{2} u}{\partial z^{2}} \cos ^{2} \theta \\
\frac{\partial^{2} u}{\partial \theta^{2}}-r \frac{\partial u}{\partial r}=\frac{\partial^{2} u}{\partial x^{2}}\left(r^{2} \cos ^{2} \theta \cos ^{2} \phi\right)+\frac{\partial^{2} u}{\partial y^{2}}\left(r^{2} \cos ^{2} \theta \sin ^{2} \phi\right)+\frac{\partial^{2} u}{\partial z^{2}}\left(r^{2} \sin ^{2} \theta\right) \\
\frac{\partial^{2} u}{\partial \phi^{2}}+r \sin ^{2} \theta \frac{\partial u}{\partial r}+\sin \theta \cos \theta \frac{\partial u}{\partial \theta}=\frac{\partial^{2} u}{\partial x^{2}}\left(r^{2} \sin ^{2} \theta \sin ^{2} \phi\right)+\frac{\partial^{2} u}{\partial y^{2}}\left(r^{2} \sin ^{2} \theta \cos ^{2} \phi\right)
\end{gathered}
$$

Dengan menggunakan invers matriks pada persamaan (6), (7) dan (8) diperoleh persamaan Laplace pada koordinat bola

Atau

$$
\begin{aligned}
\nabla^{2} u= & \frac{\cos ^{2} \theta}{r^{2}\left(\cos ^{2} \theta-\sin ^{2} \theta\right)} \frac{\partial^{2} u}{\partial \theta^{2}}+\frac{\cos ^{2} \theta}{r\left(\cos ^{2} \theta-\sin ^{2} \theta\right)} \frac{\partial u}{\partial r}-\frac{\sin ^{2} \theta}{\left(\cos ^{2} \theta-\sin ^{2} \theta\right)} \frac{\partial^{2} u}{\partial r^{2}} \\
& +\frac{1}{r^{2} \sin ^{2} \theta} \frac{\partial^{2} u}{\partial \phi^{2}}+\frac{1}{r} \frac{\partial u}{\partial r}+\frac{\cos \theta}{r^{2} \sin \theta} \frac{\partial u}{\partial r}-\frac{\cos ^{2} \theta}{r^{2}\left(\cos ^{2} \theta-\sin ^{2} \theta\right)} \frac{\partial^{2} u}{\partial \theta^{2}} \\
& -\frac{\sin ^{2} \theta}{r\left(\cos ^{2} \theta-\sin ^{2} \theta\right)} \frac{\partial u}{\partial r}+\frac{\cos ^{2} \theta}{\left(\cos ^{2} \theta-\sin ^{2} \theta\right)} \frac{\partial^{2} u}{\partial r^{2}}
\end{aligned}
$$

$$
\nabla^{2} u=\frac{\partial^{2} u}{\partial r^{2}}+\frac{2}{r} \frac{\partial u}{\partial r}+\frac{1}{r^{2}} \frac{\partial^{2} u}{\partial \theta^{2}}+\frac{1}{r^{2}} \frac{\cos \theta}{\sin \theta} \frac{\partial u}{\partial \theta}+\frac{1}{r^{2}} \frac{1}{\sin ^{2} \theta} \frac{\partial^{2} u}{\partial \phi^{2}}
$$

\section{Menentukan Solusi Persamaan Laplace pada Koordinat Bola}

Bentuk umum persmaan Laplace $\nabla^{2} u=0$ pada persamaan (9) diperoleh persamaan diferensial parsial pada persamaan laplace dimensi tiga (koordinat bola) yang dapat disederhankan

$$
\nabla^{2} u=\frac{1}{r^{2}} \frac{\partial}{\partial r}\left(r^{2} \frac{\partial u}{\partial r}\right)+\frac{1}{r^{2} \sin \theta} \frac{\partial}{\partial \theta}\left(\sin \theta \frac{\partial u}{\partial \theta}\right)+\frac{1}{r^{2} \sin ^{2} \theta} \frac{\partial^{2} u}{\partial \phi^{2}}=0
$$

dengan menggunkan metode pemisahan variabel, misalkan $u(r, \theta, \phi)$ adalah solusi dari persamaan (10) yang diasumsikan dalam bentuk variabel terpisah

$$
u(r, \theta, \phi)=R(r) P(\theta) Q(\phi)
$$


faktorisasi persamaan (10) yaitu $\frac{1}{R(r) P(\theta) Q(\phi)}$ maka diperoleh persamaan diferensial biasa (11)

$$
\frac{P Q}{r^{2}} \frac{d}{d r}\left(r^{2} \frac{d R}{d r}\right)+\frac{R Q}{r^{2} \sin \theta} \frac{d}{d \theta}\left(\sin \theta \frac{d P}{d \theta}\right)+\frac{R P}{r^{2} \sin ^{2} \theta} \frac{d^{2} Q}{d \phi^{2}}=0
$$

Berdasarkan metode pemisahan variabel diperoleh persamaan (12) dan (13)

$$
\begin{gathered}
\frac{1}{R} \frac{d}{d r}\left(r^{2} \frac{d R}{d r}\right)=-\lambda^{2} \\
\frac{1}{P \sin \theta} \frac{d}{d \theta}\left(\sin \theta \frac{d P}{d \theta}\right)+\frac{1}{Q \sin ^{2} \theta} \frac{d^{2} Q}{d \phi^{2}}=\lambda^{2}
\end{gathered}
$$

(dengan $\lambda$ adalah konstantaa bernilai riil)

maka solusi umum dari persamaan Laplace $\nabla^{2} u=0$ pada koordinat bola

$$
\begin{gathered}
R=A_{1} r^{\gamma}+\frac{B_{1}}{r^{\gamma+1}} \\
P=A_{2} S_{n}^{m}(\cos \theta)+B_{2} T_{n}^{m}(\cos \theta) \\
\mathrm{Q}=A_{3} \cos m \phi+B_{3} \sin m \phi
\end{gathered}
$$

persamaan Laplace $\nabla^{2} u=0$ pada koordinat bola diberikan oleh:

$$
\begin{gathered}
u(r, \theta, \phi)=R(r) P(\theta) Q(\phi) \\
u=\left[A_{1} r^{n}+\frac{B_{1}}{r^{n+1}}\right]\left[A_{2} S_{n}^{m}(\cos \theta)+B_{2} T_{n}^{m}(\cos \theta)\right]\left[A_{3} \cos m \phi+B_{3} \sin m \phi\right]
\end{gathered}
$$

Fungsi $u(r, \theta, \phi)$ adalah fungsi periodik dengasn periode $2 \pi$ pada $\phi$, maka $m$ haruslah bilangan bulat, yang dalam hal ini diambil positif. Untuk suatu kejadian $m=0$ solusi $u(r, \theta, \phi)$ tidak bergantung pada $\phi$ sehinnga solusi umum dari persamaan Laplace $\nabla^{2} u=0$ pada koordinat bola:

$$
u=\left[A_{1} r^{n}+\frac{B_{1}}{r^{n+1}}\right]\left[A_{2} S_{n}^{m}(\cos \theta)+B_{2} T_{n}^{m}(\cos \theta)\right]
$$

\section{PEMBAHASAN}

Hartanto, (2008) mengkaji persamaan Laplace yang digunakan yaitu persamaan Laplace dalam pelat persegi panjang dan pelat cakram untuk memperoleh solusi umum dan menyelesaikan sistem persamaan linear yang diperoleh dari metode pemisahan variabel diselesaikan dengan metode iterasi Gauss-Seidel, sedangkan pada penelitian ini solusi dari $R(r)$ persamaan diferensial linear yang didapatkan diselesaikan dengan persamaan linear Cauchy, solusi dari $P(\phi)$ persamaan diferensial linear yang diperoleh diselesaikan dengan persamaan diferensial linear Legendre dan solusi dari $Q(\phi)$ persamaan diferensial biasa yang diselesaikan dengan solusi umum. Hasil penelitian keduanya menunjukkan hal yang berbeda karena ada yang menghasilkan solusi numeriknya dan ada pula hasil analitiknya.

Faradillah, (2011) mengkaji persamaan Helmholtz pada koordinat kartesian. sedangkan pada penelitian ini, persamaan yang digunakan adalah persamaan Laplace pada koordinat bola. Peneyelesaian umum keduanya berbeda karena pada persamaan Helmholtz pada koordinat kartesian.

Penyelesaian umumnya adalah $\left[a_{n} \sin \left(\frac{n x}{2}\right)\right]\left[2 b_{n} i \cos \frac{(2 n+1) \pi y}{2^{n}}\right]\left[2 c_{n} i \cos \frac{(2 n+1) \pi z}{2^{n}}\right]=\frac{1}{2}$. sedangkan persamaan Laplace pada koordinat bola penyelesaian umumnya adalah $\left[A_{1} r^{n}+\right.$ $\left.\frac{B_{1}}{r^{n+1}}\right]\left[A_{2} S_{n}^{m}(\cos \theta)+B_{2} T_{n}^{m}(\cos \theta)\right]\left[A_{3} \cos m \phi+B_{3} \sin m \phi\right]$.

Aziz dan Chandra, (2015) pada penelitian ini sistem koordinat yang digunakan adalah koordinat polar. Sedangkan pada penelitian ini, sistem koordinat yang digunakan adalah sistem koordinat bola. Dengan demikian, hasil dari penelitian ini memperoleh solusi umum persamaan Laplace 
dimensi tiga pada koordinat bola dengan menggunakan metode pemisahan variabel dan merupakan suatu solusi analitik. Sehingga berbeda dengan hasil yang diperoleh dari Hartanto, (2008) yaitu memperoleh solusi numerik dalam pelat persegi panjang dan pelat cakram dengan menggunakan metode yang sama. Berbeda juga dari penelitian Faradilla, (2011) yaitu solusi yang didapatkan pada koordinat kartesian adalah $u(x, y, z)=$ $\left[a_{n} \sin \left(\frac{n x}{2}\right)\right]\left[2 b_{n} i \cos \frac{(2 n+1) \pi y}{2^{n}}\right]\left[2 c_{n} i \cos \frac{(2 n+1) \pi z}{2^{n}}\right]=\frac{1}{2}$ dan pada koordinat bola adalah $u(r, \theta, \phi)=\left[A_{1} r^{n}+\frac{B_{1}}{r^{n+1}}\right]\left[A_{2} S_{n}^{m}(\cos \theta)+B_{2} T_{n}^{m}(\cos \theta)\right]\left[A_{3} \cos m \phi+B_{3} \sin m \phi\right]$. Berbeda juga dengan Aziz dan Chandra yaitu hasil yang diperoleh yaitu dalam domain ruang Euclid tiga dimensi pada koordinat silinder adalah $u(r, \theta)=\sum_{n=1}^{\infty} I_{0}\left(\frac{n \pi}{h} \rho\right) \sin \left(\frac{n \pi}{h} z\right)$.

\section{KESIMPULAN}

Ada dua hal yang diperoleh dari penelitian ini:

1. Hasil penelitian diperoleh persamaan Laplace dimensi tiga pada koordinat bola:

$$
\nabla^{2} u=\frac{\partial^{2} u}{\partial r^{2}}+\frac{2}{r} \frac{\partial u}{\partial r}+\frac{1}{r^{2}} \frac{\partial^{2} u}{\partial \theta^{2}}+\frac{1}{r^{2}} \frac{\cos \theta}{\sin \theta} \frac{\partial u}{\partial \theta}+\frac{1}{r^{2}} \frac{1}{\sin ^{2} \theta} \frac{\partial^{2} u}{\partial \phi^{2}}=0
$$

Solusi umum persamaan Laplace dalam bentuk variabel terpisah:

$$
u(r, \theta, \phi)=R(r) P(\theta) Q(\phi)
$$

dengan

$$
\begin{gathered}
R(r)=A_{1} r^{n}+\frac{B_{1}}{r^{n+1}} \\
P(\theta)=A_{2} S_{n}^{m}(\cos \theta)+B_{2} T_{n}^{m}(\cos \theta) \\
Q(\phi)=A_{3} \cos m \phi+B_{3} \sin m \phi
\end{gathered}
$$

Diperoleh solusi umum dari persamaan Laplace $\nabla^{2} u=0$ pada koordinat bola, yaitu $u(r, \theta, \phi)=\left[A_{1} r^{n}+\frac{B_{1}}{r^{n+1}}\right]\left[A_{2} S_{n}^{m}(\cos \theta)+B_{2} T_{n}^{m}(\cos \theta)\right]\left[A_{3} \cos m \phi+B_{3} \sin m \phi\right]$ atau

$$
u(r, \theta)=\left[A_{1} r^{n}+\frac{B_{1}}{r^{n+1}}\right]\left[A_{2} S_{n}^{m}(\cos \theta)+B_{2} T_{n}^{m}(\cos \theta)\right]
$$

Konstruksi persamaan Laplace tidak hanya dapat dihasilkan dengan menggunakan metode pemisahan variabel tetapi juga dapat dikonstruksikan dengan menggunakan Analisis vektor. Penelitian berikutnya dapat dikembangkan lagi dengan menggunakan syarat batas untuk memperoleh solusi khusus persamaan Laplace pada koordinat bola.

\section{DAFTAR PUSTAKA}

Aziz, T \& Chandra T. D. (2015). Fungsi Harmonik dan Penerapan Persamaan Laplace dalam Menyelesaikan Masalah Nilai Batas pada Koordinat Polar.

Boyce, William E., dan Diprima, Richard E. (2009). Elementary Differential Equations and Boundary Value Problems (Nintth Edition).

Faradillah, S. (2011). Analisis Persamaan Helmholtz pada Koordinat Kartesian. Universitas Islam Negeri Maulana Malik Ibrahim, Malang. 
Hartanto, S. A. (2008). Penyelesaian Numerik Persamaan Laplace dan Persamaan Poisson dalam Pelat Persegi Panjang dan Pelat Cakram Dengan Metode Beda-Hingga. Universitas Sanata Dharma, Yokyakarta.

Kartono, (1994). Penuntun Belajar Persamaan Diferensial. Yokyakarta: Andi Offset.

Kusumah. (1989). Persamaan diferensial. Jakarta: Departemen Pendidikan dan Kebudayaan.

Purnomo, D. (2016). Trigonometri (Ilmu Ukur Sudut). Jakarta: Gunung Samudera (Grup Penerbit PT Book Mart Indonesia).

Side, S. (2014). Persamaan Diferensial Parsial. Makassar: Diktat. 